\title{
A UTILIZAÇÃO DA CONTABILIDADE COMO FERRAMENTA DE APOIO AOS PECUARISTAS NO MUNICÍPIO DE ALTA FLORESTA MATO GROSSO NO ANO DE 2016
}

\section{A SUPPORT TOOL AS KEEPING THE USE TO ACCOUNTANCY IN HIGH FLOREST MUNICIPALITY MATO GROSSO IN 2016 YEAR}

\author{
Lauriano Antônio Barella \\ Faculdade de Direito da Alta Floresta - FADAF \\ Laiane Stephanie Nascimento \\ Faculdade de Direito da Alta Floresta - FADAF \\ Flávio Sobral \\ Faculdade de Direito da Alta Floresta - FADAF
}

\begin{abstract}
RESUMO
A pecuária bovina de corte tem grande representatividade econômica no Brasil, dessa forma há um grande número de produtores bovinos no país consequentemente um grande número de organizações existentes, e como toda entidade, sua gestão necessita de informações seguras para a tomada de decisão. Desse modo, o artigo a seguir aborda qual o nível da utilização das informações contábeis pelos gestores pecuaristas de gado de corte em Alta Floresta - MT, bem como os benefícios a serem obtidos com o uso regular das informações geradas pela contabilidade para a gestão da entidade pecuária. Através dessa pesquisa faz-se a explanação de conceitos básicos da pecuária bovina de corte através de uma pesquisa realizada com pecuaristas, buscando compreender a contribuição da contabilidade como ferramenta de apoio a gestão dos negócios na pecuária de corte, visto que a informação fornecida pela contabilidade é fundamental para que atividade pecuária continue se desenvolvendo a passos largos.
\end{abstract}

Palavras-Chaves: Contabilidade, Gestão, Informação, Pecuária.

\section{ABSTRACT}

The cut of beef cattle is an economic activity of great importance for Brazil's economy, and as every entity, its management requires reliable information and decision-making. Thus, 
before work addresses what level the use of accounting information for beef cattle rancher manager in Alta Floresta - MT, and the benefits to be obtained from the regular use of the information generated by accounting for the management of livestock entity. This work is the explanation of basic concepts of beef cattle through a survey of farmers, trying to understand the accounting contribution as business management support tool in beef cattle, as the information provided by accounting is critical to that cattle industry continues to develop ever faster and getting better making both accounting as livestock have a closer relationship.

Key words: Accounting, Management, Livestock, Information.

\section{INTRODUÇÃO}

A contabilidade tem como finalidade estudar e controlar o patrimônio, para fornecer informações sobre sua composição e variações, bem como sobre o resultado econômico decorrente da gestão patrimonial. A contabilidade na pecuária é uma prática mais frequente no interior do Brasil, onde ainda existem pessoas com conhecimento empírico sobre o que é contabildade e como ela pode ajudar na gestão agropecuária. Por essa razão, se faz necessário que a informação contábil, na pecuária ou em qualquer outro ramo, seja vista como uma ferramenta de apoio importante para a otimização de resultados nas organizações. A utilização da informação contábil por parte dos gestores como citado anteriormente ainda é pouco frequente para a tomada de decisões referente ao agronegócio.

A utilização da contabilidade no setor pecuário ainda é considerada por muitos uma grande dúvida, assim aparecem indagações sobre qual visão os pecuaristas tem a respeito dos contadores, como a contabilidade está inserida neste setor e se a informação gerada pelo contador é utilizada para a definição de novos projetos de investimentos e direcionamento de lucros.

O obejetivo geral é estabelecido com finalidade de resolver o problema da pesquisa. Segundo Santos (2000, p. 62) "identificado pelo uso de verbos como: comparar, critica, diferenciar, discriminar, examinar, investigar e provar". Neste contexto o objetivo geral da pesquisa é: Verificar se as informações contábeis estão sendo utilizadas de forma que possam contribuir na otimização da produção de gado de corte.

A partir do objetivo geral forma criados os seguintes objetivos específicos:

a) analisar se a tecnologia é utilizada de forma que possa diminuir custos na produção de gado de corte; 
b) averiguar se as informações contábeis são utilizadas para a distribuição de investimentos;

c) identificar qual a maior dificuldade dos pecuaristas em utilizar as informações contábeis.

\section{EMBASAMENTO TEÓRICO}

A contabilidade possui variados ramos dos mais comuns aos menos conhecidos, ramos que muitas vezes pensa se que a contabilidade é total explorada, porém é utilizada empiricamente como acontece com a contabilidade da pecuária, devido ao fato de realizar transações bastante expressivas financeiramente.

A pecuária é responsável por boa parte da economia do Brasil, fato recorrente também em Alta Floresta, interior do Estado de Mato Grosso faz se então mais uma forte razão para a contabilidade estar nela presente. Ocorrem mudanças diárias na pecuária, novos equipamentos, novas tecnicas e a contabilidade é uma ferramenta para que a pecuária cresca de forma correta, como relatam Marion e Segatti (2010):

A eficiência e o porte da pecuária exigem novos mecanismos contabéis e de controle, em funçaõ do uso cada vez maior de insumos proporcionais ao refinamento tecnológico da atividade pecuária que cresce rapidamente e se torna cada vez mais importante para a economia do Brasil. (MARION e SEGATTI, 2010)

A atividade pecuária no Brasil tem duas práticas muito desenvolvidas, a pecuária de leite é a criação de gado com o objetivo de produção de leite, em sua maioria para a indústria de laticínios, e a pecuária de corte é destinada ao abatimento dos animais e como frequente no Brasil e na região de Alta Floresta, a exportação da carne bovina para alguns países principalmente do continente asiático, como China e Japão.

A pecuária de corte é uma atividade a longo prazo, ela passa por três processos muito importantes, processos estes chamados de cria, recria e engorda. Cria é o processo que consiste na produção de bezerro em caráter natural, tal 
produção pode ser através da monta natural, onde é selecionado o reprodutor para a cobertura das matrizes, ou através do processo de inseminação artificial. Recria é o processo iniciado com a aquisição do bezerro desmamado, em fase de desenvolvimento e por último está o processo de engorda quando o bezerro está preparado para sofrer adequadamente seu desenvolvimento estrutural.

Ao ser comercializado o bezerro recebe três nomes; bezerro, novilho maagro ou novilho gordo. Com o crescimento da pecuária é muito comum que os pecuaristas optem por apenas uma das atividades em questão, pois são muitos processos e torna- se inviável lidar com todos ao mesmo tempo, já que o período de tempo é longo e gera gastos muito altos como constata Galvão (2011):

O ciclo operacional da atividade pecuária de corte é relativamente longo e pode variar do período de três a cinco anos, desde o momento em que o bezerro foi concebido, seu nascimento, seu crescimento, até o momento de sua venda, portanto o rebanho permanece por longo período em estoque gerando sempre custos ao pecuarista. (GALVÃO, 2010).

A contabilidade com tamanhos problemas apresentados por parte da pecuária tem como função transmitir informações aos gestores das entidades para que haja a melhor distribuição de recursos tratando principalmente a respeito da venda dos animais. O rabanho comercial brasileiro é o maior do mundo sugundo o Instituto Brasileiro de Geografia e Estatística (IBGE) com 212,3 milhões de cabeças apresenta problemas quando se trata de contabilidade, como a complexidade e manutenção de um bom serviço contábil, além de que os pecuaristas continuam fechados para o uso de novas técnicas, diz então Crepaldi (2011):

A maioria dos pecuaristas persistem em manter controles baseados em suas experiências adquiridas com o passar dos anos em função de possuirem uma mentalidade muito conservadora em relação a utilização de novas técnicas que poderia trazer - Ihes grandes benefícios, além de fazer com que os pecuaristas tenham um lucro muito valioso o tempo. (CREPALDI, 2011).

A gestão de uma organização pecuária é um tanto quanto complexa este ramo requer muitos investimentos e dois são muito importantes, tempo e dinheiro além de que a maioria dos gestores não se prepara para assumir tamanhas 
responsabildades, visto que eles são os grandes responsáveis por decidir qual rumos a organização irá seguir, podendo levar a entidade ao sucesso ou ao total fracasso, como destacam também Oliveira e Santos (1993):

(...) dizem que o sucesso de qualquer empresa com atividades comerciais, industriais, serviços ou propriedades rurais depende muito dentro outros fatores do gerenciamento e consequentemente da habilidade técnica e adminidtrativa proposta por parte do gestor da organização para decidir quais caminhos a organização irá percorrer e quais serão os obejetivos a serem buscados.(OLIVEIRA e SANTOS, 1993)

É preciso que os gestores das entidades pecuárias que na maioria das situações é o próprio pecuarista compreenda que a contabildade é importante para a descoberta de novos caminhos e dê oportunidades para que outros setores possam se desenvolver a passos largos assim como a pecuária.

\section{MATERIAIS E MÉTODOS}

Na metodologia do trabalho é definida a abordagem positiva através de cada etapa de estudo, tem como objetivo responder as questões propostas, como relata Silva (2000 p. 41): "a definição da abordagem metodológica do tabalho revela o tratamento que é dispensado ao relacionamento à teoria e empiria".

O procedimento metodológico adotado na pesquisa é o estatístico, como ferramenta de sistematização e tabulação das informações contidas nos questionários, no qual participaram da pesquisa um total de 35 (trinta e cinco) pessoas, de ambos os sexos.

\section{RESULTADOS E DISCUSSÃO}

Com o resultado dos questionários depois de tabulados foi possível verificar que a maioria dos pesquisados foram do sexo masculino com $80 \%$ contra $20 \%$ do sexo feminino conforme dados apresentado na Tabela 1. A maioria dos pesquisados possuem idade acima de 51 (cinquenta e um) anos com $55 \%$ e entre 
36 (trinta e seis) e 50 (cinquenta) anos com $25 \%$ do total conforme dados da Tabela 2. O tamanho da propriedade dos pecuaristas a maioria varia entre 1501 ( mil quinhentos e um) e 2500 ( dois mil e quinhentos) hectares com $65 \%$ do total dos entrevistados conforme Tabela 3. A respeito da importância da informação contábil $65 \%$ dos entrevistados acreditam que as informaçoes geradas pela contabilidade são importantes no processo de tomada de decisão apenas ás vezes, conforme dados obtidos com a Tabela 6 .

01)Qual é o seu sexo?

Tabela 1: Classificação dos Pesquisados quanto ao gênero

\begin{tabular}{|c|c|c|c|}
\hline Ordem & Respostas & Frequência & $\%$ \\
\hline Total & & 20 & $100 \%$ \\
\hline $1^{\circ}$ & Masculino & 16 & $80 \%$ \\
\hline $2^{\circ}$ & Feminino & 4 & $20 \%$ \\
\hline
\end{tabular}

Fonte: Própria

Gráfico 1: Classificação dos Pesquisados quanto ao gênero

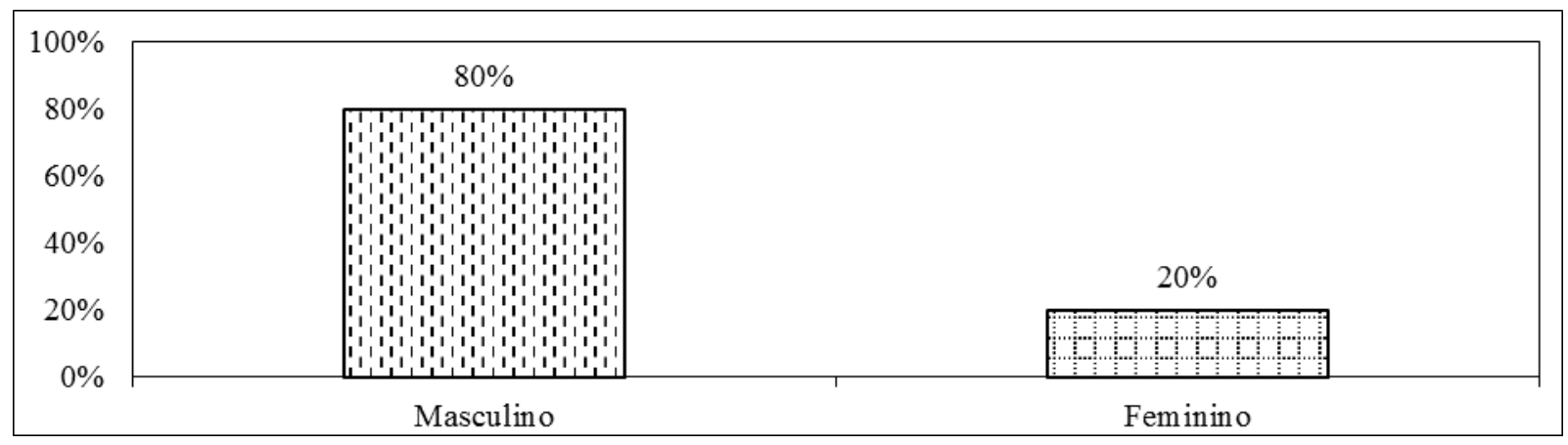

De acordo com o gráfico 1, a maioria dos pesquisados é do sexo masculino com o percentual de $80 \%$

2) Qual é a sua idade? 
Tabela 2: Faixa etária dos pesquisados

\begin{tabular}{cccc}
\hline Ordem & Respostas & Frequência & $\%$ \\
\hline Total & & 20 & $100 \%$ \\
$1^{\circ}$ & Acima de 51 anos & 11 & $55 \%$ \\
$2^{\circ}$ & Entre 36 e 50 anos & 5 & $25 \%$ \\
$3^{\circ}$ & Entre 26 e 35 anos & 3 & $15 \%$ \\
$4^{\circ}$ & Entre 18 e 25 anos & 1 & $5 \%$ \\
\hline
\end{tabular}

Fonte: Própria

Gráfico 2: Faixa etária dos pesquisados

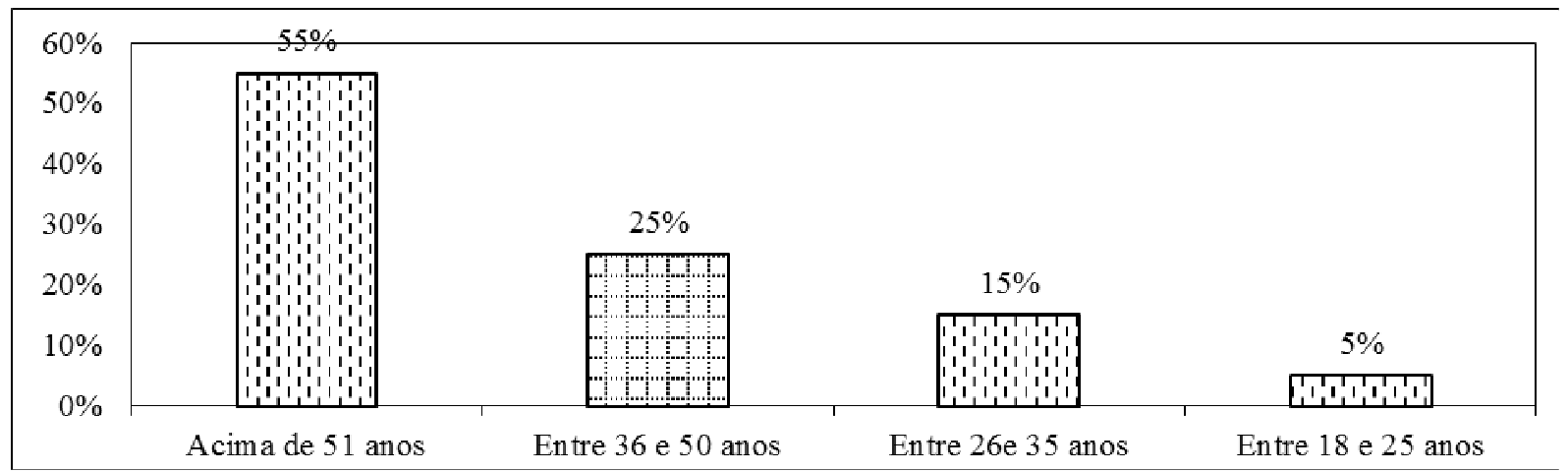

Conforme gráfico 2 a maior parte dos pesquisados possui idade acima de 51 (cinquenta e um) anos,com $55 \%$.

3) Qual é o tamanho da sua propriedade?

Tabela 3: Extensão da propriedade

\begin{tabular}{cccc}
\hline Ordem & Respostas & Frequência & $\%$ \\
\hline Total & & 20 & $100 \%$ \\
& & & \\
$1^{\circ}$ & Entre 1251 e 1750 hectares & 8 & $40 \%$ \\
$2^{\circ}$ & Entre 751 e 1250 hectares & 6 & $30 \%$ \\
& Entre 500 e 750 hectares & 5 & $25 \%$ \\
$3^{\circ}$ & Acima de 1751 hectares & 1 & $5 \%$ \\
& & & \\
\hline
\end{tabular}

Fonte: Própria 
Gráfico 3. Extensão da propriedade

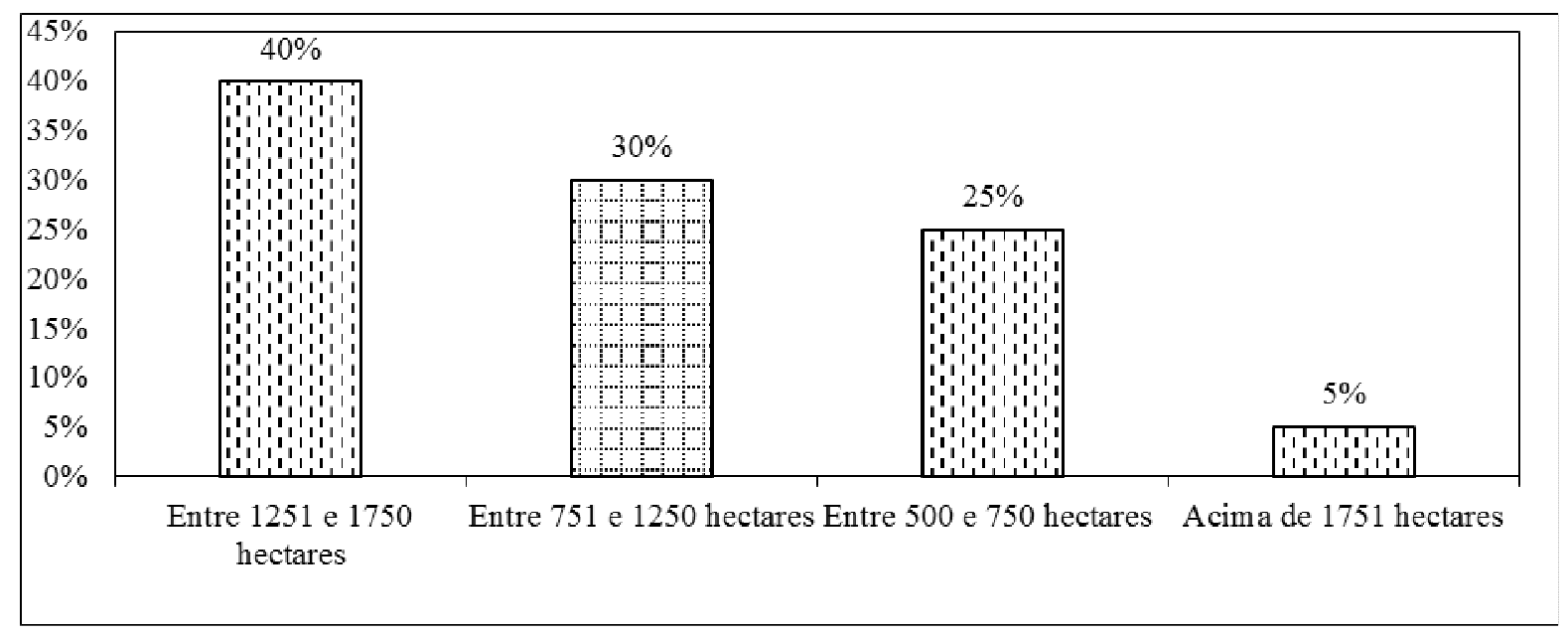

De acordo com gráfico 3, a propriedade dos pesquisados está entre 1251 (mil duzentos e cinquenta e um) e 1750 (mil setecentos e cinquenta) hectares com $40 \%$.

4) Qual é o tamanho do seu rebanho bovino?

Tabela 4: Quantidade do rebanho

\begin{tabular}{cccc}
\hline Ordem & Respostas & Frequência & $\%$ \\
\hline Total & & 20 & $100 \%$ \\
$1^{\circ}$ & Entre 1501 e 2500 cabeças & 13 & $65 \%$ \\
$2^{\circ}$ & Acima de 2501 cabeças & 4 & $20 \%$ \\
$3^{\circ}$ & Entre 501 e 1500 cabeças & 2 & $10 \%$ \\
$4^{\circ}$ & Até 500 cabeças & 1 & $5 \%$ \\
& & & \\
\hline
\end{tabular}

Fonte: Própria 
Gráfico 4: Quantidade do rebanho

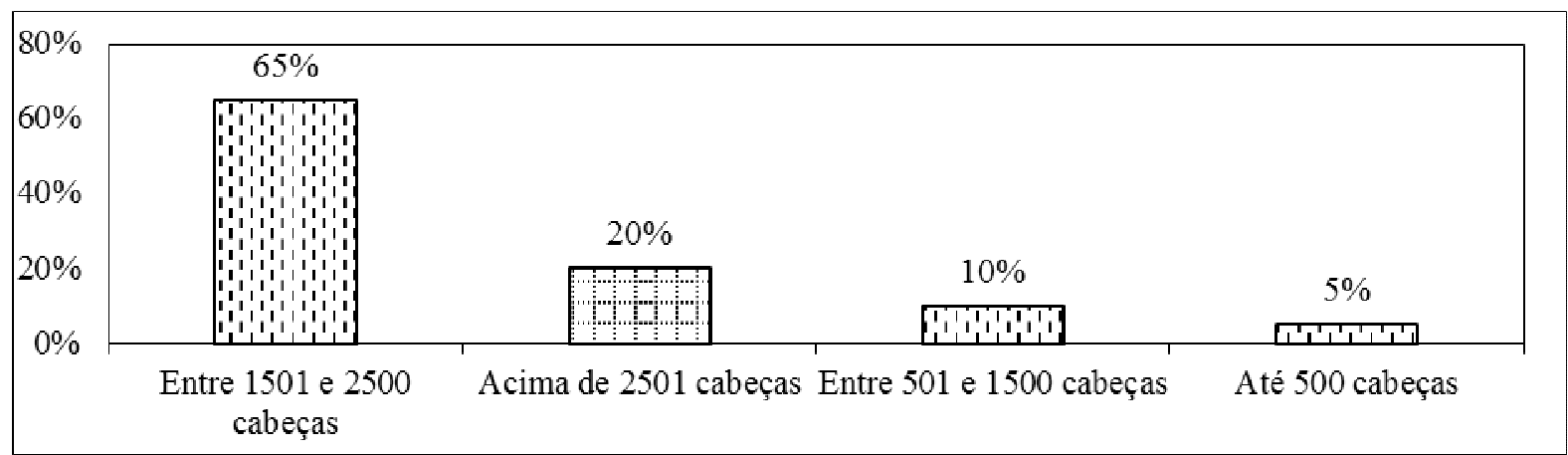

De acordo com o gráfico $4,65 \%$ dos pesquisados possui, rebanho entre 1501 (mil quinhentos e um) e 2500 (dois mil quinhentos) cabeças.

5) Quais são os serviços contábeis utilizados na gestão de seus negócios?

Tabela 5: Especificação dos serviços da contabilidade utilizados

\begin{tabular}{cccc}
\hline Ordem & Respostas & Frequência & $\%$ \\
\hline Total & & 20 & $100 \%$ \\
$1^{\circ}$ & Imposto de renda & 10 & $50 \%$ \\
$2^{\circ}$ & Guia rural & 4 & $20 \%$ \\
$2^{\circ}$ & Caixa atividade rural & 4 & $20 \%$ \\
$3^{\circ}$ & Escrita Fiscal & 1 & $5 \%$ \\
$3^{\circ}$ & Outros - Livro caixa & 1 & $5 \%$ \\
\hline
\end{tabular}

Fonte: Própria

Gráfico 5: Especificação dos serviços da contabilidade utilizados

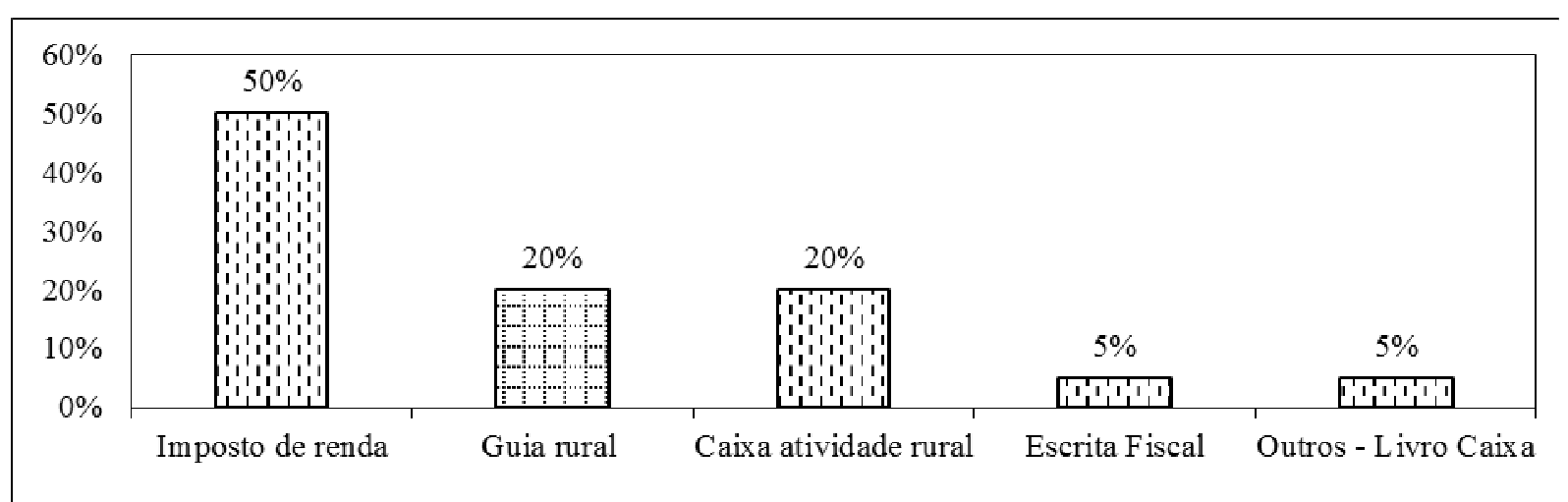

De acordo com o gráfico 5, 50\% dos pecuaristas entrevistados fazem o uso do imposto de renda como principal serviço contábil. 
6) $\mathrm{Na}$ sua opinião as informações geradas pela contabilidade são importantes no processo de decisão?

Tabela 6: Importância da informação contábil

\begin{tabular}{cccc}
\hline Ordem & Respostas & Frequência & $\%$ \\
\hline Total & & 20 & $100 \%$ \\
& & & \\
$1^{\circ}$ & Às vezes & 13 & $65 \%$ \\
$2^{\circ}$ & Raramente & 4 & $20 \%$ \\
$3^{\circ}$ & Sempre & 3 & $15 \%$ \\
$4^{\circ}$ & Nunca & 1 & $5 \%$ \\
\hline
\end{tabular}

Fonte: Própria

Gráfico 6: Importância da informação contábil

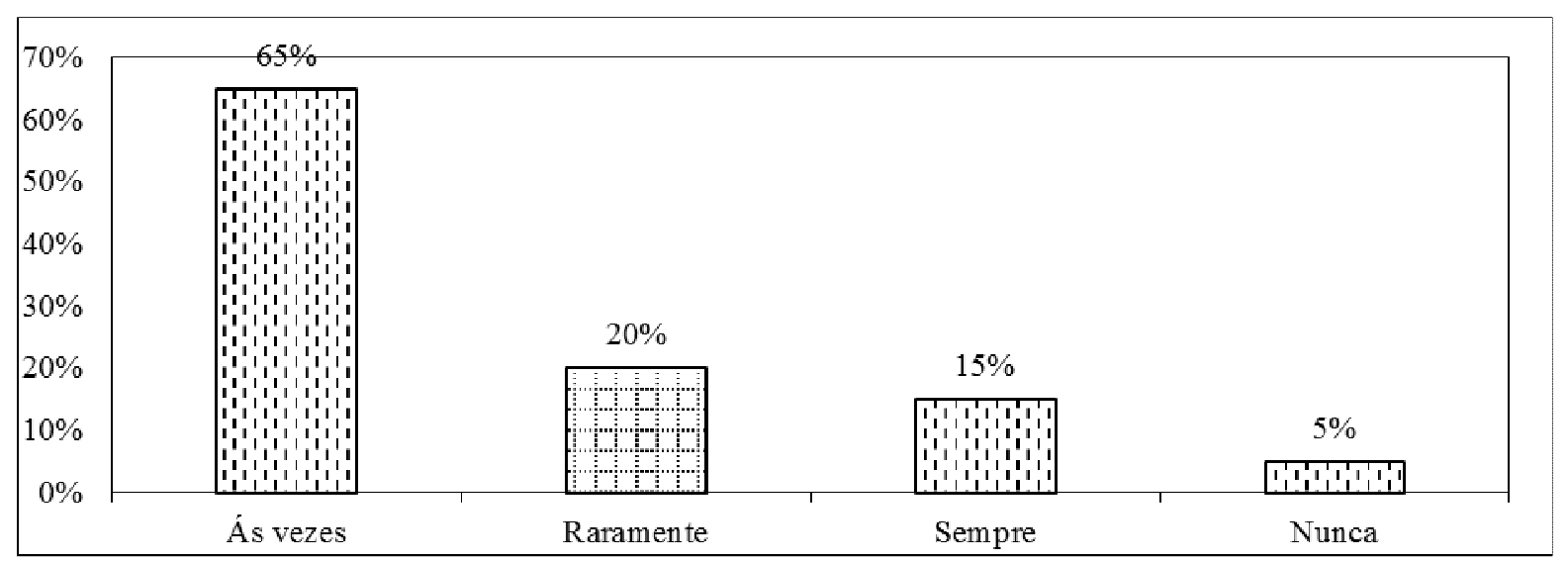

Conforme o Gráfico 6, 65\% dos pesquisados utilizam as informações contábeis apenas ás vezes.

7) A contabilidade realizada pelo seu Contador produz informações necessárias para as suas tomadas de decisões? 
Tabela 7: Produção de informações da contabilidade

\begin{tabular}{cccc}
\hline Ordem & Respostas & Frequência & $\%$ \\
\hline Total & & 20 & $100 \%$ \\
$1^{\circ}$ & Ás vezes & 8 & $40 \%$ \\
$2^{\circ}$ & Sempre & 6 & $30 \%$ \\
$3^{\circ}$ & Não tenho contador & 5 & $25 \%$ \\
$4^{\circ}$ & Não sei dizer & 1 & $5 \%$ \\
\hline
\end{tabular}

Fonte: Própria

Gráfico 7: Produção de informações da contabilidade

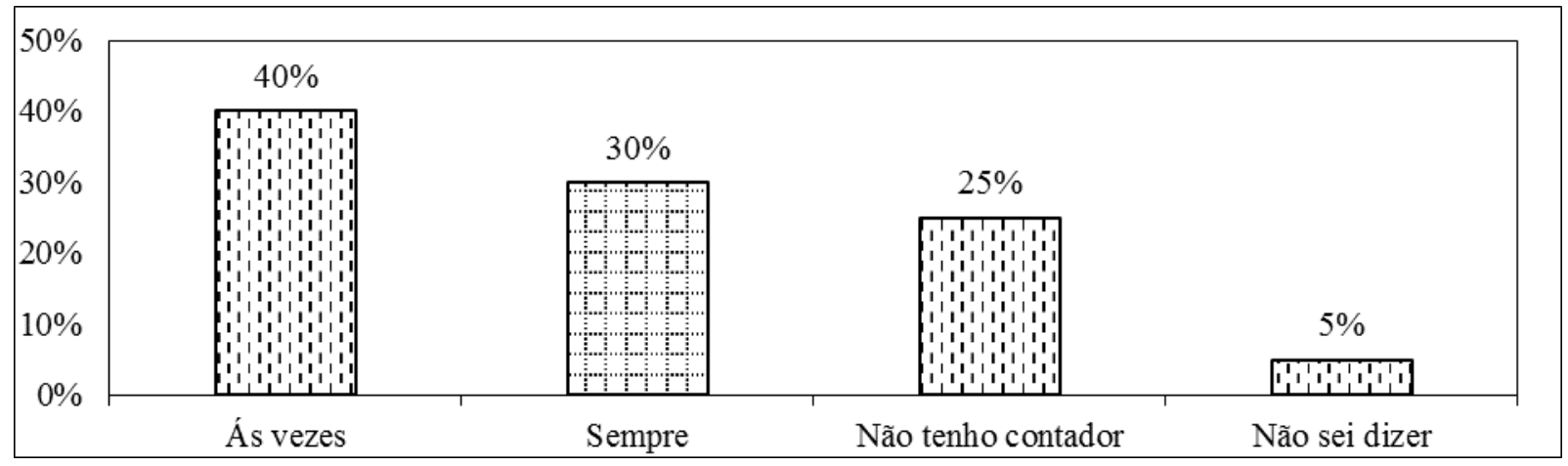

De acordo com o gráfico $7,40 \%$ dos pecuaristas pesquisados consideram as informações contábeis apenas às vezes.

8) De que forma você utiliza a tecnologia para que ela possa contribuir em seus resultados?

Tabela 8: Tecnologia na pecuária

\begin{tabular}{cccc}
\hline Ordem & Respostas & Frequência & $\%$ \\
\hline Total & & 20 & $100 \%$ \\
& Não utiliza tecnologia & 10 & $50 \%$ \\
$1^{\circ}$ & Utilização de planilhas no Excel & 4 & $20 \%$ \\
$2^{\circ}$ & Rastreamento animal & 3 & $15 \%$ \\
$3^{\circ}$ & Inseminação artificial & 3 & $15 \%$ \\
$4^{\circ}$ & & & \\
\hline
\end{tabular}

Fonte: Própria 
Gráfico 8: Tecnologia na pecuária

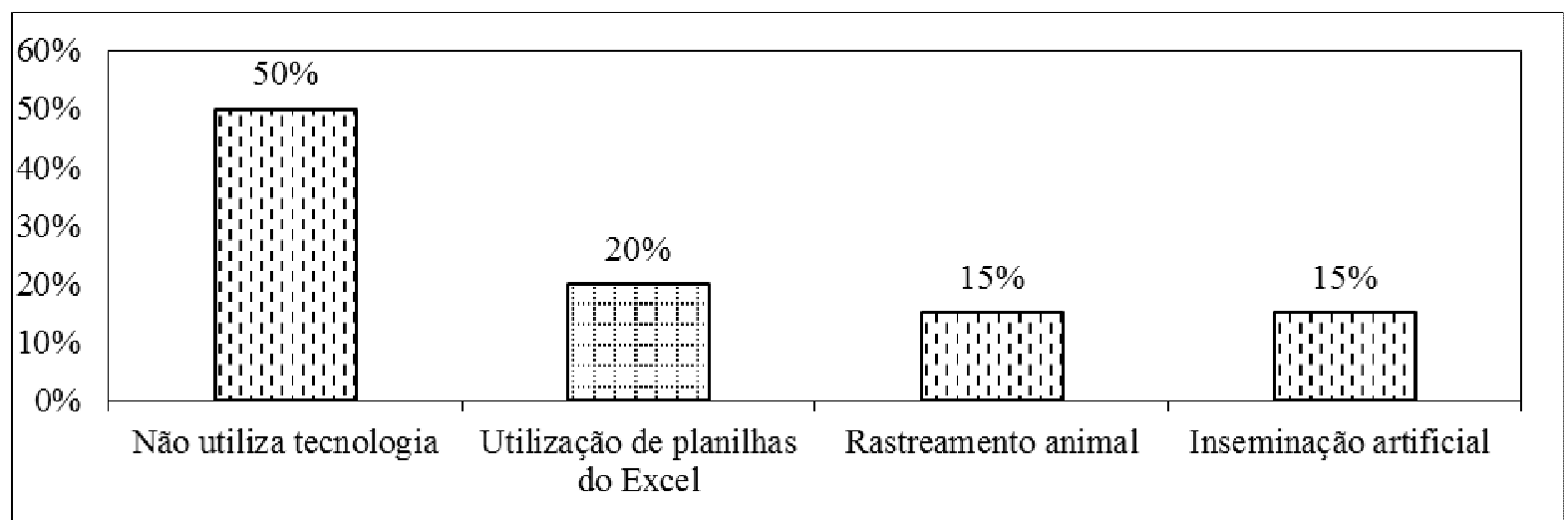

Os pecuaristas não fazem o uso da tecnologia, de acordo com o gráfico 8 com a percentagem de $50 \%$.

9) A contabilidade é utilizada por você para definir o custo da pecuária?

Tabela 9: Definição de custos da pecuária

\begin{tabular}{cccc}
\hline Ordem & Respostas & Frequência & $\%$ \\
\hline Total & & 20 & $100 \%$ \\
& Não & 10 & $50 \%$ \\
$1^{\circ}$ & Sim & 10 & $50 \%$ \\
$1^{\circ}$ & & &
\end{tabular}

Fonte: Própria

Gráfico 9: Definição de custos da pecuária

\begin{tabular}{|c|c|c|}
\hline & $50 \%$ & $50 \%$ \\
\hline $50 \%$ & 等 & 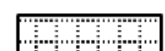 \\
\hline $40 \%$ & $\begin{array}{l}n \\
n\end{array}$ & $D_{0}$ \\
\hline $30 \%$ & 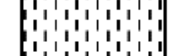 & 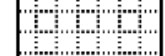 \\
\hline $20 \%$ & 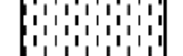 & 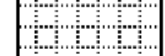 \\
\hline $10 \%$ & 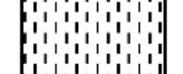 & ज्य \\
\hline & Não & Sim \\
\hline
\end{tabular}

Conforme dados da tabela $9,50 \%$ dos pecuaristas pesquisados utilizam a contabilidade para a definição de custos e $50 \%$ não fazem uso da ferramenta contábil. 
10) Realiza o planejamento a partir dos relatórios contábeis para decidir sobre novos projetos de investimentos?

Tabela 10: Planejamento a partir de relatórios contábeis

\begin{tabular}{cccc}
\hline Ordem & Respostas & Frequência & $\%$ \\
\hline Total & & 20 & $100 \%$ \\
$1^{\circ}$ & Ás vezes & 8 & $40 \%$ \\
$2^{\circ}$ & Sempre & 6 & $30 \%$ \\
$3^{\circ}$ & Raramente & 5 & $25 \%$ \\
$4^{\circ}$ & Nunca fiz uso da informação contábil & 1 & $5 \%$ \\
\hline
\end{tabular}

Fonte: Própria

Gráfico 10. Planejamento a partir de relatórios contábeis

\begin{tabular}{|c|c|c|c|c|}
\hline \multirow[t]{2}{*}{$\begin{array}{r}50 \% \\
40 \% \\
30 \% \\
20 \% \\
10 \% \\
0 \%\end{array}$} & 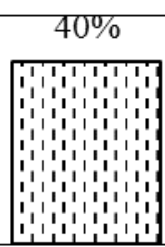 & $\begin{array}{c}30 \% \\
+4,\end{array}$ & 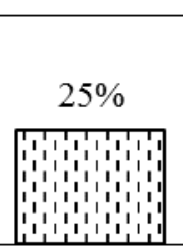 & 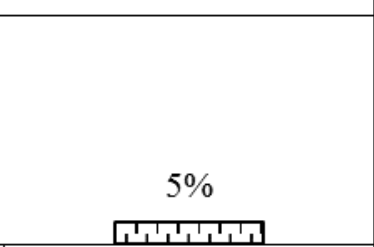 \\
\hline & Ás vezes & Sempre & Raramente & $\begin{array}{c}\text { Nunca fiz uso da } \\
\text { informação contábil para } \\
\text { fazer planejamento }\end{array}$ \\
\hline
\end{tabular}

Conforme dados presentes da tabela $10,40 \%$ dos pecuaristas fazem planejamento a partir de relatórios contábeis apenas às vezes.

11) Qual o maior benefício que o uso da informação contábil pode trazer para a gestão de sua propriedade? 
Tabela 11: Benefícios da informação contábil

\begin{tabular}{cccc}
\hline Ordem & Respostas & Frequência & $\%$ \\
\hline Total & $\begin{array}{c}\text { Facilitação no inventário } \\
1^{\circ}\end{array}$ & 6 & $100 \%$ \\
$2^{\circ}$ & Mais rapidez para o calculo do imposto & $40 \%$ \\
$3^{\circ}$ & $\begin{array}{c}\text { Mais rapidez no recebimento do } \\
\text { relatório de produção }\end{array}$ & 4 & $20 \%$ \\
$4^{\circ}$ & $\begin{array}{c}\text { Mais rapidez no recebimento do } \\
\text { relatório de custos }\end{array}$ & 3 & $15 \%$ \\
$5^{\circ}$ & $\begin{array}{c}\text { Mais rapidez no recebimento do } \\
\text { relatório de receitas e despesas }\end{array}$ & 3 & $15 \%$ \\
\hline
\end{tabular}

Fonte: Própria

Gráfico 11. Benefícios da informação contábil

\begin{tabular}{|c|c|c|c|c|c|}
\hline \multirow{3}{*}{$\begin{array}{l}35 \% \\
30 \% \\
25 \%\end{array}$} & $30 \%$ & & & & \\
\hline & 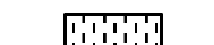 & & & & \\
\hline & 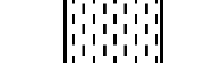 & $20 \%$ & $20 \%$ & & \\
\hline $20 \%$ & $\mid$ & $\sqrt{1,}$ & 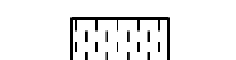 & $15 \%$ & $15 \%$ \\
\hline $15 \%$ & $\mid$ & 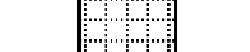 & $\left\{\begin{array}{l}1 \\
n_{1}^{\prime} \\
1 \\
1\end{array}\right.$ & 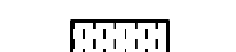 & 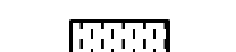 \\
\hline $10 \%$ & {$\left[\begin{array}{l}1 \\
1 \\
1\end{array}\right.$} & (1) & 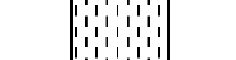 & 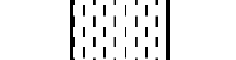 & 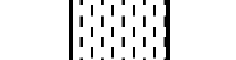 \\
\hline $5 \%$ & | & का & $\left\{\begin{array}{l}1 \\
1\end{array}\right.$ & $\left\{\begin{array}{l}1 \\
1 \\
1 \\
1\end{array}\right.$ & 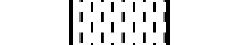 \\
\hline $0 \%$ & لני, & $=1$ & 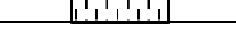 & {$[1,1,1,1$} & $\begin{array}{ll}1 \\
\end{array}$ \\
\hline & $\begin{array}{l}\text { Facilitação do } \\
\text { inventário }\end{array}$ & $\begin{array}{c}\text { Mais rapidez } \\
\text { para o cálculo do } \\
\text { imposto de renda }\end{array}$ & $\begin{array}{l}\text { Mais rapidez no } \\
\text { recebimento do } \\
\text { relatório de } \\
\text { produção }\end{array}$ & $\begin{array}{l}\text { Mais rapidez no } \\
\text { recebimento do } \\
\text { relatório de } \\
\text { custos }\end{array}$ & $\begin{array}{l}\text { Mais rapidez no } \\
\text { recebimento do } \\
\text { relatório de } \\
\text { receitas e } \\
\text { despesas }\end{array}$ \\
\hline
\end{tabular}

Segundo dados da tabela 11 , consideram com $40 \%$ que o maior benefício da informação contábil é a facilitação do inventário.

12) Na sua opinião, qual é a mudança necessária, para que a atividade pecuária utilize com maior frequência as informações fornecidas pela contabilidade? 
Tabela 12: Mudanças necessárias na atividade pecuária

\begin{tabular}{cccc}
\hline Ordem & Respostas & Frequência & $\%$ \\
\hline Total & & 20 & $100 \%$ \\
$1^{\circ}$ & Clareza na informação & 8 & $40 \%$ \\
$2^{\circ}$ & Rapidez na informação & 6 & $30 \%$ \\
$2^{\circ}$ & Valor cobrado pelo contador & 6 & $30 \%$ \\
\hline
\end{tabular}

Fonte: Própria

Gráfico 12: Mudanças necessárias na atividade pecuária

\begin{tabular}{|c|c|c|c|}
\hline $50 \%$ & $40 \%$ & & \\
\hline $40 \%$ & 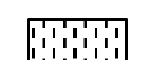 & $30 \%$ & $30 \%$ \\
\hline $30 \%$ & {$\left[\begin{array}{l}1 \\
1 \\
1 \\
1\end{array}\right.$} & 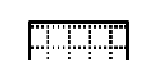 & 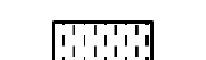 \\
\hline $20 \%$ & 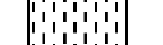 & घण & $\mid$ \\
\hline $10 \%$ & 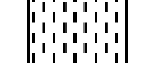 & घा। & 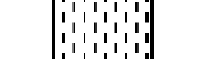 \\
\hline $0 \%$ & & & \\
\hline & $\begin{array}{l}\text { Clareza na } \\
\text { informação }\end{array}$ & $\begin{array}{l}\text { Rapidez na } \\
\text { informação }\end{array}$ & $\begin{array}{l}\text { Valor cobrado } \\
\text { pelo contador }\end{array}$ \\
\hline
\end{tabular}

Os pecuaristas relataram, como confirmam dados do gráfico 12, que o maior motivo da não utilização da informação contábil para a tomada de decisão na pecuária é a falta de clareza com $40 \%$.

13) Especifique três aspectos que você considera negativos sobre a contabilidade no ramo da pecuária.

Tabela 13: Aspectos negativos da contabilidade na pecuária

\begin{tabular}{cccc}
\hline Ordem & Respostas & Frequência & $\%$ \\
\hline Total & & 60 & $100 \%$ \\
& Falta de clareza & 19 & $31,67 \%$ \\
$1^{\circ}$ & Demora na entrega de relatórios de custos & 13 & $21,66 \%$ \\
$2^{\circ}$ & Viabilidade econômica & 10 & $16,67 \%$ \\
$3^{\circ}$ & Demora na entrega de relatórios de despesas & 9 & $15 \%$ \\
$4^{\circ}$ & Demora na entrega de relatórios de receitas & 9 & $15 \%$ \\
$4^{\circ}$ &
\end{tabular}

Fonte: Própria 
Gráfico 13: Aspectos negativos da contabilidade na pecuária

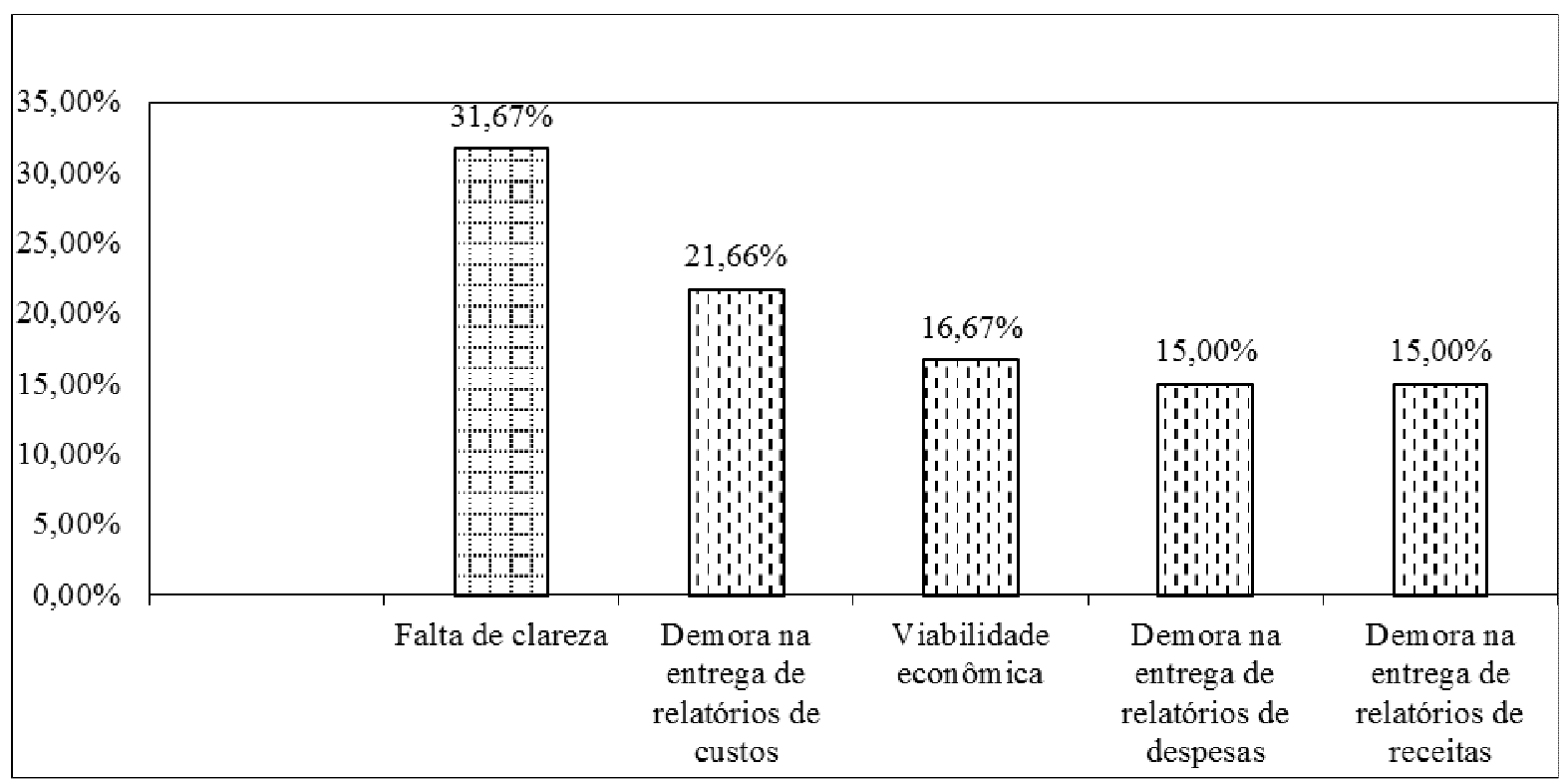

O aspecto negativo mais citado conforme gráfico 13 é a falta de clareza com $31,67 \%$ dos pesquisados.

14) Especifique três aspectos positivos que você considera importante para a utilização da informação contábil no setor pecuário.

Tabela 14: Aspectos positivos da contabilidade na pecuária

\begin{tabular}{llll}
\hline Ordem & Respostas & Frequência & $\%$ \\
\hline Total & & 59 & $100 \%$ \\
$1^{\circ}$ & Balanço patrimonial & 16 & $27,11 \%$ \\
$2^{\circ}$ & Inventário & 11 & $18,33 \%$ \\
$3^{\circ}$ & Notas explicativas & 9 & $15 \%$ \\
$3^{\circ}$ & DRE & 9 & $15 \%$ \\
$4^{\circ}$ & Parecer dos auditores & 8 & $13,33 \%$ \\
$5^{\circ}$ & Demonstração de fluxo financeiro & 6 & $10,16 \%$ \\
\hline
\end{tabular}

Fonte: Própria 
Gráfico 14: Aspectos positivos da contabilidade na pecuária

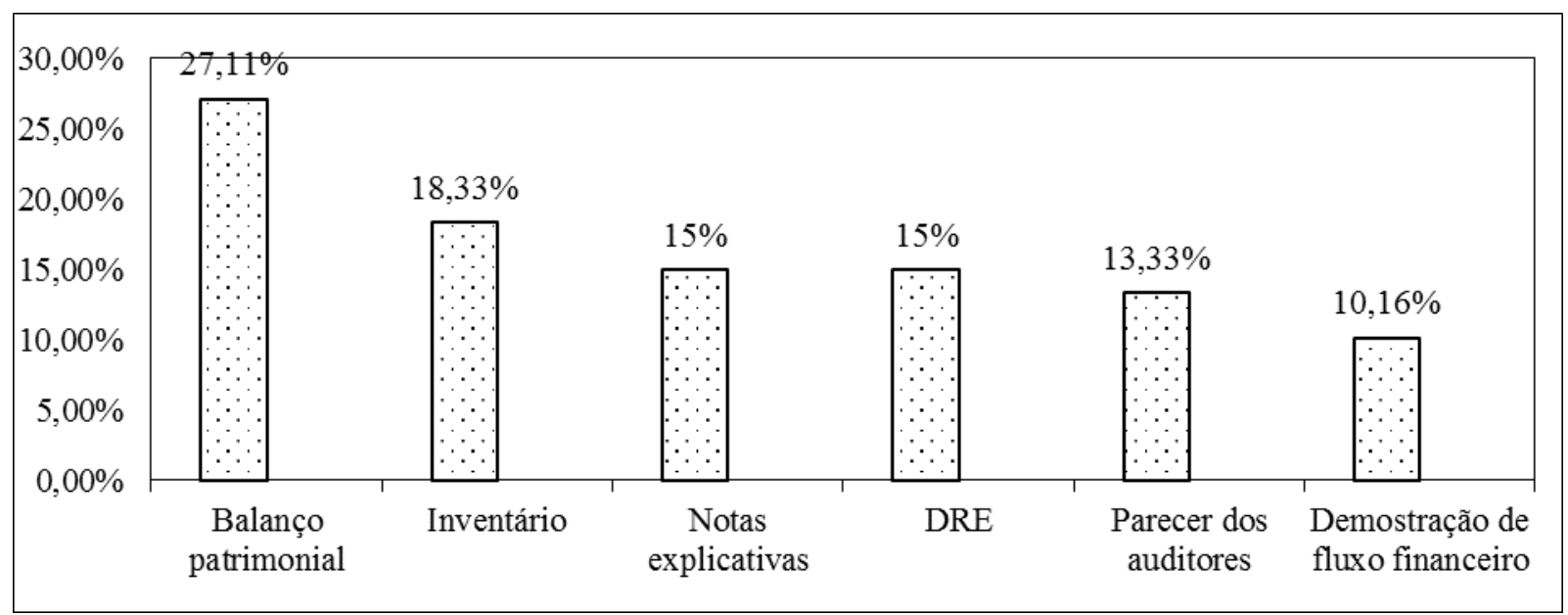

O aspecto positivo mais citado pelos pecuaristas conforme gráfico 14 , é o uso do balanço patrimonial com $27,11 \%$ dos pesquisados.

15) Quais são os fatores que dificultam a utilização da informação contábil no processo de tomada de decisão na administração de seus negócios?

Tabela 15: Descrição dos fatores que dificultam o uso da informação contábil

\begin{tabular}{cccc}
\hline Ordem & Respostas & Frequência & $\%$ \\
\hline Total & & 20 & $100 \%$ \\
$1^{\circ}$ & Alto custo do contador & 9 & $45 \%$ \\
$2^{\circ}$ & Falta de clareza & 4 & $20 \%$ \\
$3^{\circ}$ & Tempo & 3 & $15 \%$ \\
$4^{\circ}$ & Distância & 2 & $10 \%$ \\
$4^{\circ}$ & Falta de conhecimento por parte dos & 2 & $10 \%$ \\
\hline
\end{tabular}

Fonte: Própria 
Gráfico 15. Descrição dos fatores que dificultam o uso da informação contábil

\begin{tabular}{|c|c|c|c|c|c|}
\hline \multirow{5}{*}{$\begin{array}{r}50 \% \\
40 \% \\
30 \% \\
20 \% \\
10 \% \\
0 \%\end{array}$} & \multicolumn{5}{|l|}{$45 \%$} \\
\hline & 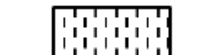 & & & & \\
\hline & 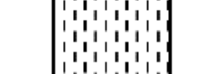 & $20 \%$ & $15 \%$ & & \\
\hline & 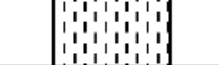 & प, & 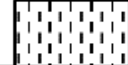 & 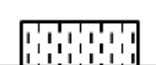 & 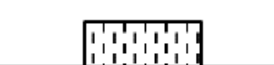 \\
\hline & $\begin{array}{l}\text { Alto custo do } \\
\text { contador }\end{array}$ & Falta de clareza & Tempo & Distância & $\begin{array}{l}\text { Falta de } \\
\text { conhecimento por } \\
\text { parte dos } \\
\text { contadores }\end{array}$ \\
\hline
\end{tabular}

De acordo com dados do gráfico 15, o alto custo do contador é uma das razões que interferem o uso da informação contábil na administração.

16) Deixe a sua sugestão em relação a contabilidade para que seja mais utilizada no setor pecuário.

Tabela 16: Sugestões para a contabilidade ser mais utilizada

\begin{tabular}{|c|c|c|c|}
\hline Ordem & Respostas & Frequência & $\%$ \\
\hline Total & & 20 & $100 \%$ \\
\hline $1^{\circ}$ & Entender o que se trata & 6 & $30 \%$ \\
\hline $1^{\circ}$ & $\begin{array}{c}\text { Saber os benefícios que a contabilidade } \\
\text { pode trazer }\end{array}$ & 6 & $30 \%$ \\
\hline $3^{\circ}$ & Saber onde ela pode utilizada & 4 & $20 \%$ \\
\hline $4^{\circ}$ & $\begin{array}{c}\text { Saber como a contabilidade pode ser } \\
\text { utilizada }\end{array}$ & 4 & $20 \%$ \\
\hline
\end{tabular}

Fonte: Própria

Gráfico 16: Sugestões para a contabilidade ser mais utilizada

\begin{tabular}{|c|c|c|c|c|}
\hline \multirow{2}{*}{$\begin{array}{l}40 \% \\
30 \%\end{array}$} & $30 \%$ & $30 \%$ & & \\
\hline & 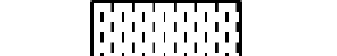 & का & $20 \%$ & $20 \%$ \\
\hline $20 \%$ & & 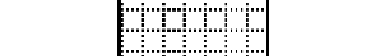 & 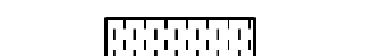 & 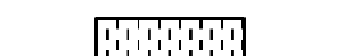 \\
\hline $10 \%$ & $\begin{array}{l}n \\
0\end{array}$ & en, & 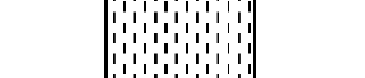 & \\
\hline $0 \%$ & Entender o que se trata & ss benefićós que a & ber como ela pode ser & ela pode ser \\
\hline
\end{tabular}


Conforme dados relatados no gráfico 16 , é importante que os pecuaristas entendam do que se trata para poder fazer o uso da informação contábil com $30 \%$ e também saber os benefícios que ela pode trazer.

\section{CONSIDERAÇÕES FINAIS}

Por intermédio da pesquisa constatou - se que os pecuaristas apresentam receio sobre a contabilidade, pois não sabem quais mudanças sua utilização podem provocar, tendo em vista como o resultado que a maior dificuldade é a falta de clareza. Diante de todos os resultados obtidos pode - se constatar que os pecuaristas apresentam curiosidade, sobre como utilizar a contabilidade sendo um aspecto positivo, pois os mesmos deixaram suas sugestões e recomendações para a maior utilização. Beneficiando assim os contadores os pecuaristas e o consumidor final.

Sendo que nos dias de hoje ocorrem transformações rápidas, fazendo com que assim exista maior competitividade e se faz necessário que todas as partes envolvidas no processo estejam em harmonia para que os resultados possam ser considerados satisfatórios.

\section{REFERÊNCIAS}

ASSOCIAÇÃO BRASILEIRA DE NORMAS TÉCNICAS. NBR 6022: Informação e documentação - Artigo em publicação periódica científica impressa - Apresentação. Rio de Janeiro: ABNT, 2003.

ASSOCIAÇÃO BRASILEIRA DE NORMAS TÉCNICAS: NBR 6023: informação e documentação: referências: elaboração. Rio de Janeiro, 2002. Janeiro, 2003.

NBR 6024: numeração progressiva das seções de um documento. Rio de

NBR 6027: informação e documentação: sumário: apresentação. Rio de Janeiro, 2003.

NBR 10520: informação e documentação: citações em documentos: apresentação. Rio de Janeiro, 2002. 
NBR 14724: informação e documentação: trabalhos acadêmicos: apresentação. Rio de Janeiro, 2011.

Crepalidi, Silvio Aparecido. Contabilidade Rural: uma abordagem decisorial. 6. ed. São Paulo: Atlas, 2011.

Lakatos, E. M. ; Marconi, M. de Andrade. Metodologia do trabalho científico. 6. ed. São Paulo: Atlas, 2001.

Marion, José Carlos; Segatti, Sônia. Contabilidade da Pecuária. 9. ed. São Paulo: Atlas, 2010.

Marion, José Carlos. Contabilidade Rural: contabilidade agrícola, contabilidade da pecuária e imposto de renda - pessoa jurídica. 12. ed. São Paulo: Atlas, 2010.

Oliveira, Neuza Corte de. Contabilidade do Agronegócio: teoria e prática: 2. ed. Curitiba: Juruá Editora, 2011

PORTAL BRASIL. Rebanho bovino brasileiro cresce e chega a 212,3 milhões de cabeças de gado. Disponível em < http://www.brasil.gov.br/economia-eemprego/2015/10/rebanho-bovino-brasileiro-cresce-e-chega-a-212-3-milhoes-decabecas-de-gado > Acessado em 16 de Maio de 2016.

Tobias, José Antonio. Como fazer sua pesquisa. 5. ed. São Paulo: Ave Maria, 2006. 